\title{
Estrogen Receptor $\alpha$ Regulates Insulin Sensitivity through IRS-1 Tyrosine Phosphorylation in Mature 3T3-L1 Adipocytes
}

\author{
KAZUHIKO MURAKI, SHIGERU OKUYA AND YUKIO TANIZAWA \\ Division of Endocrinology, Metabolism, Hematological Sciences and Therapeutics, Department of Bio-Signal Analysis, Yamaguchi \\ University Graduate School of Medicine, 1-1-1 Minami-Kogushi, Ube, Yamaguchi 755-8505, Japan
}

\begin{abstract}
There are many clinical and experimental reports demonstrating that estrogens and insulin interact when affecting their target organs. Estrogen receptors consist of two isoforms, estrogen receptors-alpha (ER- $\alpha$ ) and -beta (ER$\beta$ ), but their roles in insulin-induced glucose uptake in mature adipose tissue have yet to be clarified. To evaluate the roles of ER- $\alpha$, expressed predominantly in adipocytes, we have investigated the effects of estradiol (E2), an ER- $\alpha$ selective agonist (PPT), and its selective antagonist (MPP) on glucose uptake and insulin action in 3T3-L1 adipocytes. 3T3-L1 adipocytes were exposed to E2 or PPT and/or MPP at different concentrations. The cells were then subjected to 2-deoxyD-glucose transport assay, western blot analysis, or RT-PCR analysis. Treatment of these cells with E2 or PPT resulted in biphasic effects on glucose transport, that is high $\left(10^{-5} \mathrm{M}\right.$ or $3 \times 10^{-6} \mathrm{M}$ each $)$ and low $\left(10^{-8} \mathrm{M}\right)$ doses produced inhibition and stimulation, respectively. The favorable effect observed at $10^{-8} \mathrm{M}$ of E2 was diminished by treatment with MPP. Western bolt analysis revealed that these effects of E2, PPT and MPP paralleled the level of IRS-1 tyrosine phosphorylation. However, IRS-1 serine phosphorylation, suppressor of cytokine signaling (SOCS)-1,-2,-3 and protein tyrosine phosphatase 1B (PTP1B) expression did not change compaired to control subjects. Our data clearly show that ER- $\alpha$ contributes to insulin stimulated glucose uptake through regulation of the tyrosine phosphorylation of IRS-1 protein.
\end{abstract}

Key words: ER- $\alpha$, Estradiol, IRS-1, Tyrosine phosphorylation, Adipocyte

(Endocrine Journal 53: 841-851, 2006)

THERE is a great deal of clinical and experimental evidence demonstrating that sex steroids and insulin interact in exerting their effects on insulin targeting organs [1]. In clinical studies, high concentrations of estrogens, as in pregnancy [2,3], trans-sexuality [4] and during menstrual cycles [5], appear to contribute to the development of insulin resistance. On the other hand, there is considerable evidence against adverse effects of estrogens on glucose metabolism and some for beneficial actions of estrogen. In male mice with complete aromatase deficiency, which are unable to

Received: January 12, 2006

Accepted: March 10, 2006

Correspondence to: Dr. Yukio TANIZAWA, Division of Endocrinology, Metabolism, Hematological Sciences and Therapeutics, Department of Bio-Signal Analysis, Yamaguchi University Graduate School of Medicine, 1-1-1 Minami-Kogushi, Ube, Yamaguchi 755-8505, Japan catalyze the formation of estrogens from androgens, progressive insulin resistance is observed [6]. Ovaryectomized (OVX) mice are more insulin-resistant than sham controls and treatment of these OVX mice with estrogen normalizes both glucose tolerance and insulin sensitivity [7]. These results suggest the necessity for appropriate estrogen concentrations to maintain insulin sensitivity, while excessively high concentrations lead to deterioration of insulin sensitivity.

Estrogens mediate their effects through two receptor isoforms, estrogen receptor alpha (ER- $\alpha$ ) and estrogen receptor beta (ER- $\beta$ ), each of which is responsible for different biological functions as reflected by their tissue-specific expression patterns. Different roles have been assigned to ER- $\alpha$ and ER- $\beta$ in mediating the effects of estrogens in adipose tissue. This was suggested by the observations that ER- $\alpha$ gene knockout mice become obese, whereas ER- $\beta$ knockout mice have a normal amount of adipose tissue [8-10]. Furthermore, 
in human adipocytes, the level of ER- $\beta$ mRNA is much lower than that of ER- $\alpha$ mRNA [11]. These findings indicate that $\mathrm{ER}-\alpha$ might play a major role in mediating the effects of estrogens on adipocytes.

In recent years, ER subtype-selective agonists and antagonists contributing to the functional study of these ER subtypes have been developed. Katzenellenbogen et al. $[12,13]$ have developed compounds that are capable of stimulating ER- $\alpha$ very selectively. Propylpyrazole triol (PPT), a member of the triarylpyrazole class, is more than 10,000-fold more potent on ER- $\alpha$ than on ER- $\beta[12,13]$. Recently, Katzenellenbogen et al. developed a compound known to antagonize ER$\alpha$, but not ER- $\beta$, by adding basic side-chains typically found in non steroidal anti-estrogens to pyrazole compounds, and this specific antagonist was named methylpiperidino-pyrazole (MPP) [14]. These compounds would presumably be useful for studying the functions of ER- $\alpha$ in adipocytes.

Although evidence that very low and high concentrations of estrogen can cause insulin resistance has been obtained in clinical studies, relatively little information is available on the molecular basis of this mechanism. In vitro, culture of 3T3-L1 adipocytes with high concentrations of estrogens (estrone, estradiol or estriol) resulted in a reduced ability of insulin to stimulate glucose uptake by attenuating insulin signaling events, leading to GLUT4 translocation to the plasma membrane [15]. This study suggests that these estrogens can modulate insulin sensitivity and contribute to the development of insulin resistance by acting directly on adipocytes, but the precise role of ER subtypes was not examined. With the use of an ER- $\alpha$ selective agonist (PPT) and a selective antagonist (MPP), we investigated the role of ER- $\alpha$ in insulin sensitivity in mature 3T3-L1 adipocytes. Furthermore, we examined mechanisms of insulin sensitivity associated with estrogen.

\section{Materials and Methods}

\section{Materials and antibodies}

We obtained E2 (1,3,5[10]-Estratriene-3,17(-diol), cell culture tested) and PPT (1,3,5-Tris (4-hydroxyphenyl)-4-propyl-1H-pyrazole) from Sigma (St. Louis, MO, USA). MPP (1,3-Bis (4-hydroxyphenyl)-4-methyl5-[4-(2-piperidinylethoxy)phenol]-1H-pyrazole dihydrochloride) was from Tocris (St. Louis, MO, USA). Anti
IRS-1 rabbit polyclonal, anti-Akt1 and anti-GLUT4 antibodies were from Santa Cruz Biotechnology (Santa Cruz, CA, USA). Phospho Akt (serine 473), phospho IRS-1 (serine 307), phospho IRS-1 (serine 612) and phospho Erk antibodies were purchased from Cell Signaling Technology (Beverly, MA, USA). Anti-insulin receptor beta subunit (IR $\beta$ ) antibody was obtained from BD Transduction Laboratories (San Diego, CA, USA). Anti-Erk antibody was purchased from New England Biolabs (Beverly, MA, USA). Anti-GAPDH antibody was from CHEMICON (Temecula, CA, USA). Other reagents are described below.

\section{Cell culture and differentiation}

We grew 3T3-L1 fibroblasts in DMEM-HG (Dulbecco's Modified Eagle Medium-high glucose), 10\% bovine calf serum at $37^{\circ} \mathrm{C}$ in $10 \% \mathrm{CO}_{2}$ and split the cultures at about $30 \%$ confluence. Cells for use in experiments were grown in the same medium until 2 days after confluence, and then differentiated into adipocytes by treatment with induction medium $(0.7 \mu \mathrm{M}$ insulin, $0.1 \mu \mathrm{g} / \mathrm{ml}$ dexamethasone, and $0.5 \mathrm{mM} 3-$ isobutyl-1-methylxanthine) [17]. The cells treated with induction medium for 3 days were incubated in DMEM-HG and $10 \%$ fetal bovine serum (FBS). The cells were used for experiments at least 8 days after differentiation. After 6 days' induction, our 3T3-L1 fibroblasts are fully differentiated. Because the differentiated cells tend to be dislodged from the culture dishes or plates after 14 days' culture, we completed the experiments before 11 days after the induction. Phenol red-free medium and charcoal-stripped FBS was used while incubating the cells with E2, PPT or MPP to eliminate estrogenic effects of the medium. Phenol red is known to exert weak estrogenic effects [18].

\section{2-deoxy-D-glucose transport assays}

3T3-L1 adipocytes on 24-well plates were pretreated in DMEM-HG, 10\% FBS containing E2 or other compounds (PPT or MPP) for $24 \mathrm{~h}$, then deprived of serum by incubation for $3 \mathrm{~h}$ in KRH buffer ( $25 \mathrm{mM}$ HEPES, pH 7.4, $120 \mathrm{mM} \mathrm{NaCl}, 5 \mathrm{mM} \mathrm{KCl}, 1.2 \mathrm{mM} \mathrm{MgSO}_{4}$, $1.3 \mathrm{mM} \mathrm{CaCl}_{2}$ and $1.3 \mathrm{mM} \mathrm{K \textrm {K } _ { 2 }} \mathrm{PO}_{4}$ ) containing E2, PPT or MPP. E2 and PPT were dissolved in ethanol, MPP in water. The cells were then stimulated with $100 \mathrm{nM}$ insulin for $15 \mathrm{~min}$. Glucose transport assay 
was initiated by the addition of 2-[ $\left.{ }^{3} \mathrm{H}\right]$ deoxy-D-glucose to a final concentration of $100 \mu \mathrm{M}$ 2-deoxy-D-glucose $(20 \mu \mathrm{Ci} / \mathrm{mmol})$. After 5 minutes, the incubation transport assay was terminated with rapid washing in icecold KRH buffer three times. The cells were recovered by adding $0.5 \mathrm{ml} /$ well of $0.1 \mathrm{~N} \mathrm{NaOH}$, and radioactivity was measured by liquid scintillation counting.

\section{Immunoprecipitation}

3T3-L1 adipocytes grown in 6-well plates were preincubated in DMEM-HG, 10\% FBS containing E2 or chemical compounds (PPT or MPP) for $12 \mathrm{~h}$, then deprived of serum by incubation for $12 \mathrm{~h}$ in serum-free DMEM-HG containing E2, PPT or MPP. Cells were solubilized with lysis buffer (20 mM HEPES, pH 7.4, $100 \mathrm{mM} \mathrm{NaCl}, 1 \mathrm{mM}$ EDTA, $1 \% \mathrm{NP}-40,25 \mathrm{mM}$ $\mathrm{NaF}, 1 \mathrm{mM}$ sodium orthovanadate, $1 \mathrm{mM}$ benzamidine, $5 \mu \mathrm{g} / \mathrm{ml}$ leupeptin, $5 \mu \mathrm{g} / \mathrm{ml}$ aprotinin, $1 \mathrm{mM}$ DTT and $1 \mathrm{mM}$ phenylmethylsulfonyl fluoride (PMSF)). To examine IRS-1 phosphorylation, $500 \mu \mathrm{g}$ of total cell lysates were subjected to immunoprecipitation for $1 \mathrm{~h}$ at $4{ }^{\circ} \mathrm{C}$ with polyclonal antibody to IRS-1 $(1 \mu \mathrm{g})$.

\section{SDS-PAGE and immunoblotting}

Total cell lysates and immunoprecipitates were resolved by SDS-PAGE on $8 \%$ gels and transferred to PVDF (Amersham, Piscataway, NJ, USA) membrane. Immunolabelled proteins were visualized using HRPconjugated secondary antibodies and the ECL system (Amersham, Piscataway, NJ, USA). Bands were analyzed and quantified using NIH Image version 1.62.

\section{Isolation of RNA and cDNA synthesis}

3T3-L1 adipocytes on 6-well plates were incubated in DMEM-HG, $10 \%$ FBS for $12 \mathrm{~h}$, then in serum free, DMEM-HG medium containing E2 or PPT for $12 \mathrm{~h}$, and finally washed twice with ice-cold PBS. Cells were homogenized in ISOGEN (NIPPON GENE, Tokyo, Japan), and total RNA was extracted following the manufacturer's protocol.

Total RNA $(1 \mu \mathrm{g})$ was converted to cDNA utilizing oligo-dT primer and Super Script II (Invitrogen, Carlsbad, CA, USA) in a total reaction volume of $20 \mu \mathrm{l}$ containing $1 \times$ RT buffer, $0.5 \mathrm{mM}$ dNTP, $0.01 \mathrm{M}$ DTT, and 40 units of ribonuclease inhibitor (RNAsin, Promega, Madison, WI, USA). The reaction mixture was incubated at $65^{\circ} \mathrm{C}$ for $5 \mathrm{~min}, 42^{\circ} \mathrm{C}$ for $50 \mathrm{~min}$ and terminated by increasing the temperature to $70^{\circ} \mathrm{C}$ for $15 \mathrm{~min}$ in a thermal cycler as described by the manufacturer.

\section{$P C R$ and Semi quantitative RT-PCR}

PCR and semi quantitative RT-PCR were performed in a total reaction volume of $20 \mu \mathrm{l}$ containing oligonucleotide primers $(0.2 \mu \mathrm{M}), 1 \times$ PCR buffer, $1.5 \mathrm{mM}$ $\mathrm{MgCl}_{2}, 0.2 \mathrm{mM}$ dNTP, and 0.5 units of Taq DNA polymerase (Roche, Basel, Switzerland).

Primers for ER- $\alpha,-\beta$ (16), suppressor of cytokine signaling (SOCS)-1, SOCS-2, SOCS-3, PTP1B and glyceraldehydes-3-phosphate dehydrogenase (GAPDH) were as follows, ER- $\alpha$ : sense 5'-GGCCTGACTCTG CAGCAGCAG-3', anti-sense 5'-GTTGGGGAAGCC CTCTGCTTC-3' (annealing temp. $65^{\circ} \mathrm{C}, 300$-bp product), ER- $\beta$ : sense 5'-GGCATTCTACAGTCCTGCTG3', antisense 5'-TCTGCATAGAGAAGCGATGA-3' (annealing temp. $60^{\circ} \mathrm{C}$ 165-bp product), SOCS-1: sense 5'-CAGACACAAGCTGCTACAACC-3', antisense 5'-CGTGACTACCTGAGTTCCTTCC-3' (annealing temp. $58^{\circ} \mathrm{C}, 274$-bp product), SOCS-2: sense 5'-CGCGTCTGGCGAAAGCCCTGC-3', antisense 5'-CATTAACAGTCATACTTCCCCAGTACC-3' (annealing temp. $68^{\circ} \mathrm{C}, 69$-bp product), SOCS-3: sense 5'-CACAGCAAGTTTCCCGCCGCC-3', antisense 5'GTGCACCAGCTTGAGTACACAGTC-3' (annealing temp. $68^{\circ} \mathrm{C}, 365$-bp product), PTP1B: sense 5'CTCCTGAACAGGTTAAGGCC-3', antisense CTG GTCAATGTGTGCATGG-3' (annealing temp. $56^{\circ} \mathrm{C}$, 269-bp product), GAPDH: sense CAGACACAAGC TGCTACAACC-3', antisense CGTGACTACCTGAG TTCCTTCC-3' (annealing temp. $68^{\circ} \mathrm{C}, 100$-bp product). Exactly $4 \%$ of the first strand cDNA of each sample was used for PCR amplification by the specific primers indicated above. The reaction mixtures were incubated in a thermal cycler for 40 (ER- $\alpha$, ER- $\beta$ ), 35 (SOCS-1, SOCS-2, SOCS-3), 26 (PTP1B) and 23 cycles (GAPDH) as follows: at $94^{\circ} \mathrm{C}$ for $60 \mathrm{sec}$, at annealing temperatures indicated for $60 \mathrm{sec}$ and at $72^{\circ} \mathrm{C}$ for $60 \mathrm{sec}$. In semiquantitative RT-PCR for SOCS-1, SOCS-2, SOCS-3, PTP1B and GAPDH, the cycles were terminated during the phase in which there was exponential generation of PCR products before reaching a plateau. After the cycles had been completed, the tubes were maintained at $72^{\circ} \mathrm{C}$ for $10 \mathrm{~min}$. Twenty microliters of the PCR product were analyzed on $2 \%$ 
agarose gel in the presence of ethidium bromide. Bands were analyzed and quantified using NIH Image version 1.62.

\section{Statistical analysis}

The statistical significance of differences in measured quantities was determined with Student's $t$-test. A $P$ value less than 0.05 was considered statistically significant. Average values were expressed as means \pm standard error of the mean (SEM).

\section{Results}

\section{PCR for ER- $\alpha$ and - $\beta$ in mature 3T3-L1 adipocytes}

To determine the functional role of ER- $\alpha$ in mature adipocytes, we studied 3T3-L1 adipocytes that had been cultured for more than 8 days after the induction of differentiation. 3T3-L1 cells subjected to such longterm culture are considered to be representative of mature adipocytes, given that the expression of proteins linked to adipocyte differentiation does not change significantly after 8 days of such treatment [19]. To confirm the expressions of ER- $\alpha$ and $-\beta$, mRNA expressions of both ERs on fully differentiated 3T3-L1 adipocytes were examined by the RT-PCR method. ER- $\alpha$ and $-\beta$ were both expressed in the mature 3T3-L1 adipocytes used in our present experiments (Fig. 1).

\section{2-deoxy-D-glucose transport assay during treatment with E2, PPT and MPP}

The 3T3-L1 adipocytes we used in the series of experiments were fully differentiated, and no apparent change was observed by the E2 or PPT and/or MPP

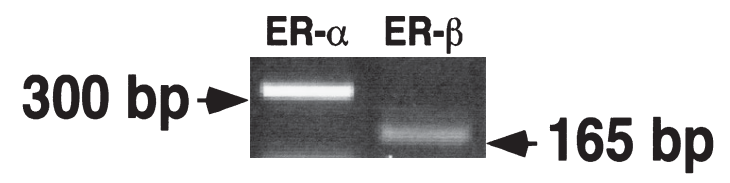

Fig. 1. RT-PCR analysis for ER- $\alpha$ and $-\beta$ mRNA expressions in mature 3T3-L1 adipocytes.

PCR products were applied to $2 \%$ agarose gel (left: ER$\alpha$, right: ER- $\beta$ ). The sizes of PCR products for ER- $\alpha$ and $-\beta$ are $300 \mathrm{bp}$ and $165 \mathrm{bp}$, respectively. The RTPCR results shown are representative of three separate experiments with the same protocol. treatment on inspection.

We first examined the effects of several concentrations of E2 on 2-deoxy-D-glucose transport. 3T3-L1 adipocytes pretreated with E2 for $24 \mathrm{~h}$ were compared with cells exposed to the same concentration of vehicle (ethanol: EtOH).

We consistently observed that insulin-stimulated deoxyglucose transport was significantly reduced $(29 \%$ reduction compared to control samples) by treatment with E2 at $10^{-5} \mathrm{M}$ for $24 \mathrm{~h}(P<0.01)$ (Fig. 2A). On the other hand, E2 treatment at $10^{-8} \mathrm{M}$ for $24 \mathrm{~h}$ significantly increased insulin-stimulated deoxyglucose transport $(P<0.05)$ (Fig. 2A).

To investigate whether ER- $\alpha$ contributes to the effects observed with E2 treatment, we next examined deoxyglucose transport using PPT, a selective ligand for ER- $\alpha$. Treatment of cells with PPT at concentrations of $10^{-6}$ and $3 \times 10^{-6} \mathrm{M}$ decreased insulinstimulated deoxyglucose uptake by $15 \%$ and $39 \%$, respectively, as compared to vehicle treated controls $(P<0.01)$ (Fig. 2B). The increase in deoxyglucose uptake seen with E2 at $10^{-8} \mathrm{M}$ was also seen at the PPT concentration of $10^{-8} \mathrm{M}(P<0.05)$ (Fig. 2B).

To confirm that the effects observed with E2 treatment occurred via ER- $\alpha$, we compared the E2 $10^{-8} \mathrm{M}$ treated cells with those to which MPP at $10^{-6} \mathrm{M}$ had been added. Increased insulin-stimulated deoxyglucose uptake observed with E2 treatment at $10^{-8} \mathrm{M}$ was not recognized when the cells were co-incubated with MPP (Fig. 2C). Incubation of the cells in DMEM containing MPP only had no effect on deoxyglucose transport (data not shown). Unfortunately, we could not test whether the inhibitory effect of a high E2 concentration on insulin stimulated glucose uptake also occurs through ER- $\alpha$, because this would require a very high concentration of MPP.

Biphasic changes of insulin-stimulated glucose uptake were not associated with the amount of GLUT4 protein expression (Fig. 2D).

Effects of E2 $\left(10^{-5} \mathrm{M}\right)$ or PPT $\left(3 \times 10^{-6} \mathrm{M}\right)$ treatment on protein expression and insulin-stimulated phosphorylation of insulin signaling molecules

We next investigated the effects of a high concentration of E2 or PPT on the molecules involved in insulin signaling for glucose transport. Cells pretreated for $24 \mathrm{~h}$ with a high concentration of E2 $\left(10^{-5} \mathrm{M}\right)$ or PPT $\left(3 \times 10^{-6} \mathrm{M}\right)$ were incubated in the presence or absence 
of $100 \mathrm{nM}$ insulin for 3 minutes at $37^{\circ} \mathrm{C}$. Incubation in a high concentration of PPT $\left(3 \times 10^{-6} \mathrm{M}\right)$ or E2 $\left(10^{-5}\right.$ $\mathrm{M})$ resulted in significant inhibition of insulin-induced tyrosine phosphorylation of IRS-1 (Fig. 3A (b), Fig. 3B (b)) and serine phosphorylation of Akt, a signaling molecule downstream from IRS-1 (Fig. 3A (c), Fig. 3B (c) $(P<0.05)$. However, high concentrations of $\mathrm{E} 2$ and

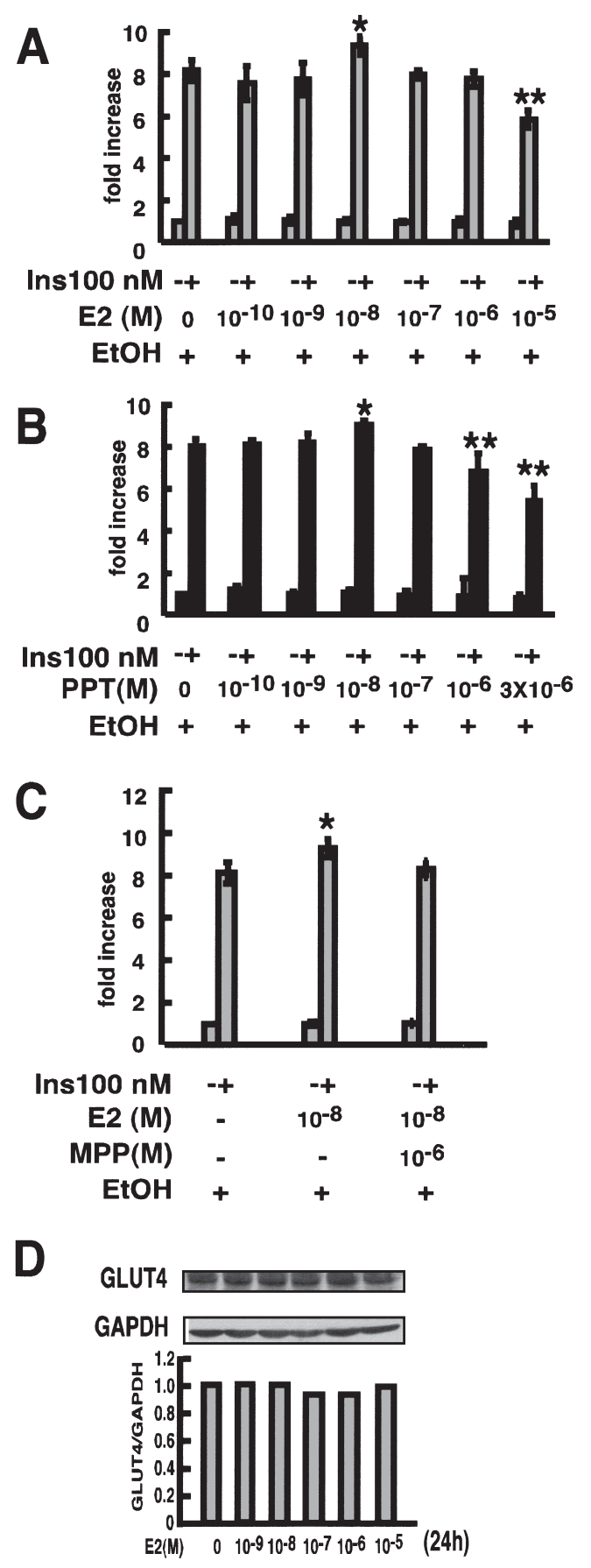

Fig. 2
PPT had no effect on the abundance of IR $\beta$ (Fig. 3A (a), Fig. 3B (a)), IRS-1 (Fig. 3A (b), Fig. 3B (b)), Akt proteins (Fig. 3A (c), Fig. 3B (c)), or the insulinstimulated tyrosine phosphorylation of IR $\beta$ (Fig. 3A (a), Fig. 3B (a)). These findings indicate that high concentrations of E2 and PPT produce insulin resistance at the IRS-1 level of the insulin signaling pathway. To evaluate the IR-Erk pathway, we simultaneously analyzed Erk protein expression and phosphorylation of Erk. However, neither changed and these results indicate E2 and PPT to specifically impair IRS-1 tyrosine phosphorylation (Fig. 3A (d), Fig. 3B (d)).

\section{Effects of E2 $\left(10^{-8} \mathrm{M}\right)$ plus MPP $\left(10^{-6} \mathrm{M}\right)$ treatment on insulin stimulated phosphorylation of insulin signaling molecules}

Next, we investigated whether the regulations by

Fig. 2. Measurement of 2-deoxy-D-glucose transport after treatment with E2, PPT and MPP.

(A) Effects of E2 on 2-deoxy-D-glucose transport in 3T3-L1 adipocytes. 3T3-L1 adipocytes were treated with vehicle (EtOH) or E2 at the indicated concentrations for $24 \mathrm{~h}$. (B) Effects of PPT on 2-deoxy-Dglucose transport in 3T3-L1 adipocytes. 3T3-L1 adipocytes were treated with vehicle $(\mathrm{EtOH})$ or PPT at the range of indicated concentrations for $24 \mathrm{~h}$. After serum starvation, the cells were incubated for an additional $15 \mathrm{~min}$ with or without $100 \mathrm{nM}$ insulin. Data are means \pm standard error of the mean (SEM) for five independent experiments, each performed in triplicate, and are expressed relative to the value for control cells without $100 \mathrm{nM}$ insulin. Significant differences in comparison with the control $(100 \mathrm{nM}$ insulin without E2) are indicated: $* P<0.05, * * P<0.01$. (C) Effects of MPP treatment on 2-deoxy-D-glucose uptake in 3T3-L1 adipocytes incubated with E2 at $10^{-8} \mathrm{M}$ for $24 \mathrm{~h}$. 3T3-L1 adipocytes were treated with EtOH, E2 at $10^{-8} \mathrm{M}$ or E2 at $10^{-8} \mathrm{M}$ plus MPP at $10^{-6} \mathrm{M}$ for $24 \mathrm{~h}$, and then incubated with or without $100 \mathrm{nM}$ insulin for $15 \mathrm{~min}$. Significant differences in comparison with the control $(100 \mathrm{nM}$ insulin without E2) are indicated: $* P<0.05$. (D) 3T3-L1 adipocytes treated with indicated concentrations of E2 for $24 \mathrm{~h}$ were analyzed by western blotting. The cells were solubilized and immunoblotted as described in Materials and Methods, and each band was then quantified by NIH image version 1.62. GLUT4 protein was detected using anti-GLUT4 antibody, and the same membrane was then stripped and re-blotted with anti-GAPDH antibody. The amount of GLUT4 protein was normalized by the amount of GAPDH protein, and expressed relative to that of the E2 (-) control. Data are representative of three independent experiments. 
tyrosine phosphorylation of IRS-1 observed in E2 and PPT at high concentrations also occur at a relatively low concentration of E2 $\left(10^{-8} \mathrm{M}\right)$. After all, tyrosine phosphorylation of IR $\beta$ did not change, while tyrosine phosphorylation of IRS-1 was increased (Fig. 4A, Fig. 4B). Furthermore, we used an ER- $\alpha$ selective antago- nist, MPP, to examine whether the regulation of IRS-1 tyrosine phosphorylation was through ER- $\alpha$ or ER- $\beta$ activation. With simultaneous addition of MPP and E2, the tyrosine phosphorylation level of IRS-1 returned to the control level (Fig. 4B).
A

(a) total IR $\beta$
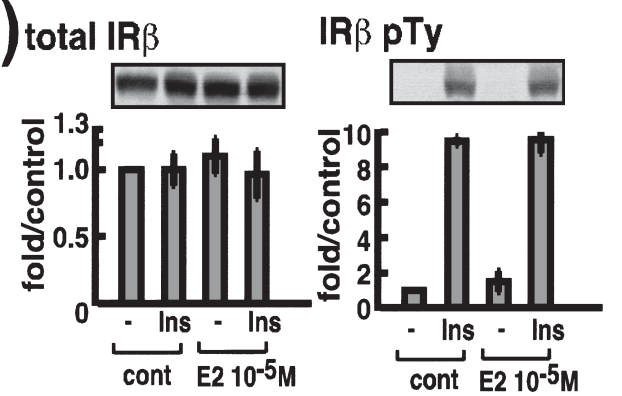

IRS-1 pTy

(b)

total IRS-1

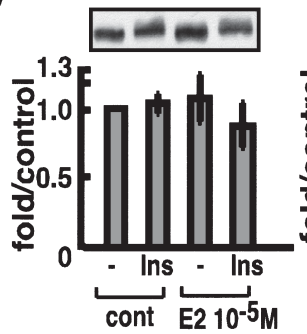

(C) total Akt

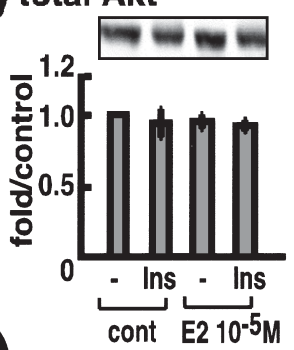

(d) total Erk
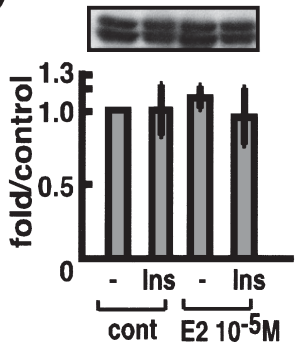

IB:PTy

IB:IRS-1 $-0-a$

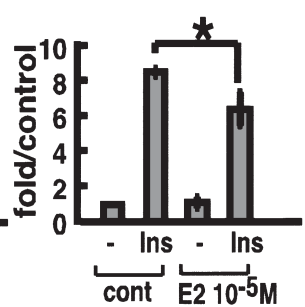

phospho Akt

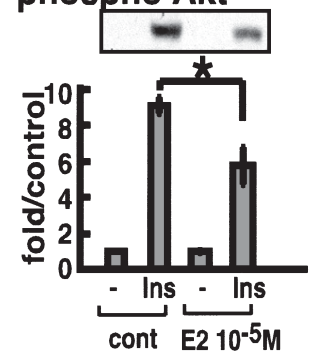

phospho Erk

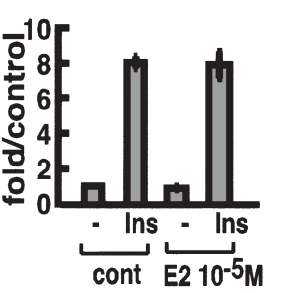

(a) total IR
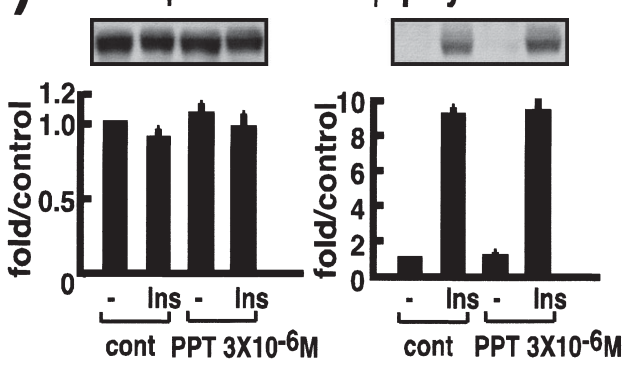

IRS-1 pTy

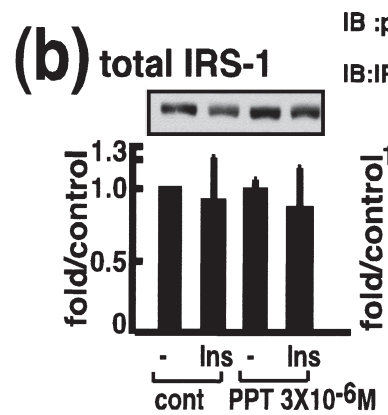

IB :pTy

IB:IRS-1

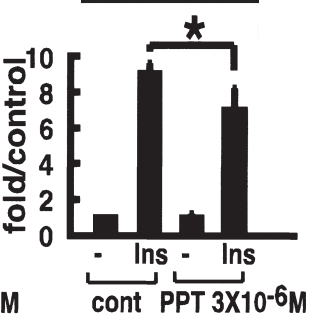

(c)

total Akt

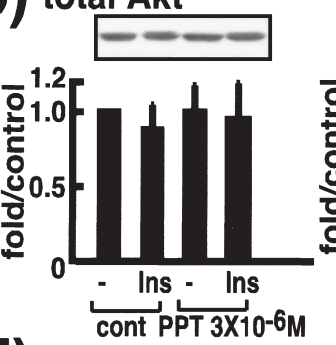

(d)

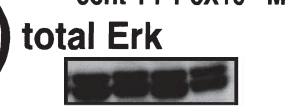

phospho Akt

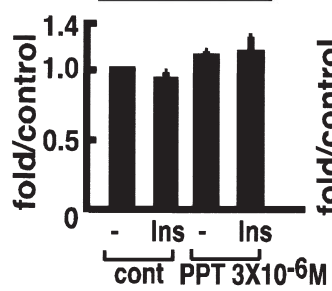

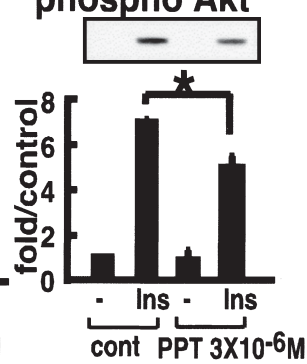

phospho Erk

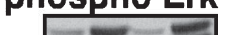

E=

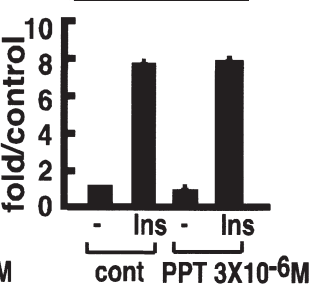

Fig. 3 
Effects of E2 on IRS-1 protein serine phosphorylation and on MRNA expression of SOCS1-3 and PTP1B in mature 3T3-L1 adipocytes

Finally, we reviewed serine phosphorylation of IRS1 protein and expression of the mRNAs of SOCS-1, 2, 3 and PTP1B to examine how E2 regulates IRS-1 tyrosine phosphorylation.

Though IRS-1 has many serine phosphorylation sites, we selected serine 307 and 612 as representative serine phosphorylation sites [20]. A high concentration of E2 $\left(10^{-5} \mathrm{M}\right)$, which decreased IRS-1 tyrosine phosphorylation, did not increase IRS-1 serine phos-

Fig. 3. Effects of a high concentration of E2 or PPT on protein expression and phosphorylations of IR $\beta$, IRS-1, Akt and Erk.

3T3-L1 adipocytes were treated with or without E2 $\left(10^{-5} \mathrm{M}\right)$ or PPT $\left(3 \times 10^{-6} \mathrm{M}\right)$ for $24 \mathrm{~h}$ and then incubated for an additional 3 minutes with or without $100 \mathrm{nM}$ insulin (Ins) at $37^{\circ} \mathrm{C}$. The cells were solubilized, immunoprecipitated and immunoblotted as described in Materials and Methods, and each band was then quantified by NIH image version 1.62. A: 3T3-L1 adipocytes treated with a high concentration of E2 were analyzed by western blotting. (a) IR $\beta$ protein was detected using anti-IR $\beta$ antibody (left panel and graph) and the same membrane was then stripped and re-blotted with an antiphosphotyrosine antibody (4G10) (pTy) (right panel and graph). (b) IRS-1 protein was detected using antiIRS-1 antibody (left panel and graph). To analyze tyrosine phosphorylation of IRS-1, total cell lysates were subjected to immunoprecipitation (IP) with antibody against IRS-1. Resulting precipitates were subjected to immunoblot analysis (IB) with antibody to IRS-1, and the same membrane was then stripped and re-blotted with anti-phosphotyrosine antibody (4G10) (right panel and graph). (c) Akt protein was detected using anti-Akt antibody (left panel and graph), and the same membrane was then stripped and re-blotted with an anti-phospho Akt antibody (right panel and graph). (d) Erk protein was detected using anti-Erk antibody (left panel and graph), and the same membrane was then stripped and re-blotted with an anti-phospho Erk antibody (right panel and graph). B: 3T3-L1 adipocytes treated with a high concentration of PPT were analyzed by western blotting. Experiments in Figure 3B-(a) (b) (c) (d) were the same as those in 3A (a) (b) (c) (d). Data are means \pm SEM of at least three independent experiments, and are expressed relative to the value for control cells without insulin. Significant differences in comparison with the control (100 nM insulin without E2 or PPT) are indicated: $* P<0.05$.

pTy, tyrosine phosphorylation. phorylation (serine 307 and 612) (Fig. 5A). We also attempted to detect JNK activation using phosphoJNK specific antibody, but found none (data not shown).

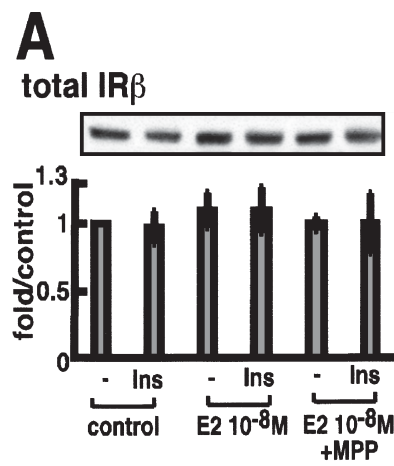

IR $\beta$ pTy
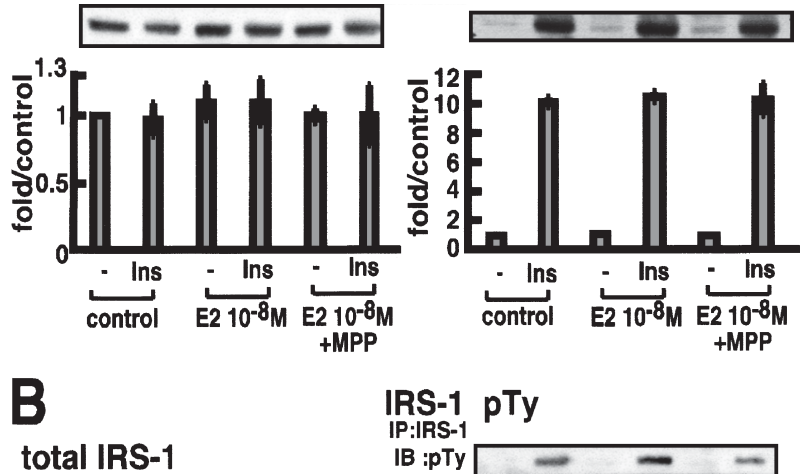

IR:IRS-1 PTy

total IRS-1
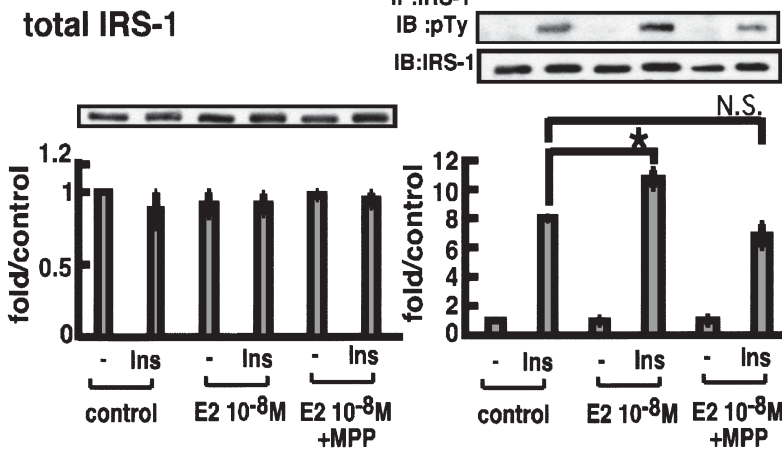

IB:IRS-1 $\longrightarrow-\infty$

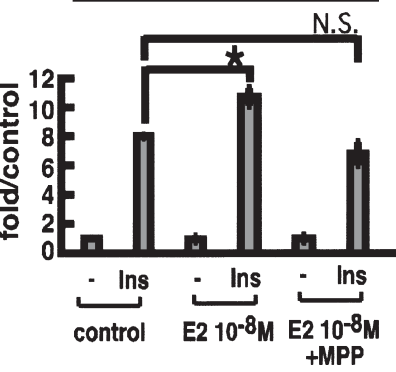

Fig. 4. Effects of E2 at $10^{-8} \mathrm{M}$ plus MPP treatment on IR $\beta$ and IRS-1 protein expression and tyrosine phosphorylation. 3T3-L1 adipocytes were treated with EtOH, E2 $\left(10^{-8}\right.$ M) and E2 $\left(10^{-8} \mathrm{M}\right)$ plus MPP $\left(10^{-6} \mathrm{M}\right)$ for $24 \mathrm{~h}$ and then incubated for an additional 3 minutes with or without $100 \mathrm{nM}$ insulin (Ins) at $37^{\circ} \mathrm{C}$. The cells were solubilized, immunoprecipitated and immunoblotted as described in Materials and Methods. Then, each band was quantified by NIH image version 1.62. A: IR $\beta$ protein was detected using anti-IR $\beta$ antibody (left panel and graph), and the same membrane was then stripped and re-blotted with an anti-phosphotyrosine antibody (4G10) (pTy) (right panel and graph). B: IRS-1 protein was detected using anti-IRS-1 antibody (left panel and graph). To analyze tyrosine phosphorylation of IRS-1, total cell lysates were subjected to immunoprecipitation (IP) with antibody to IRS-1. Resulting precipitates were subjected to immunoblot analysis (IB) with antibody to IRS-1. Then, the same membrane was stripped and re-blotted with anti-phosphotyrosine antibody (4G10) (right panel and graph). Data are means \pm SEM of three independent experiments, and are expressed relative to the value for control cells without $100 \mathrm{nM}$ insulin. Significant differences in comparison with the control (100 nM insulin without E2) are indicated: $* P<0.05$. 
We next speculated that increased expression of SOCS-1, 2, 3 or PTP1B might be involved in the regulation of IRS-1 tyrosine phosphorylation. We therefore analyzed these mRNA expressions in cells treated for $24 \mathrm{~h}$ with or without E2, at concentrations of $10^{-9}-10^{-5}$ $\mathrm{M}$, by the semi-quantitative RT-PCR method. There were no changes in the expressions of these mRNAs (Fig. 5B, C).

\section{Discussion}

In our present study on mature 3T3-L1 adipocytes, we demonstrated that exposure to high doses of E2 or PPT (from $3 \times 10^{-6} \mathrm{M}$ to $10^{-5} \mathrm{M}$ ) inhibits insulin-

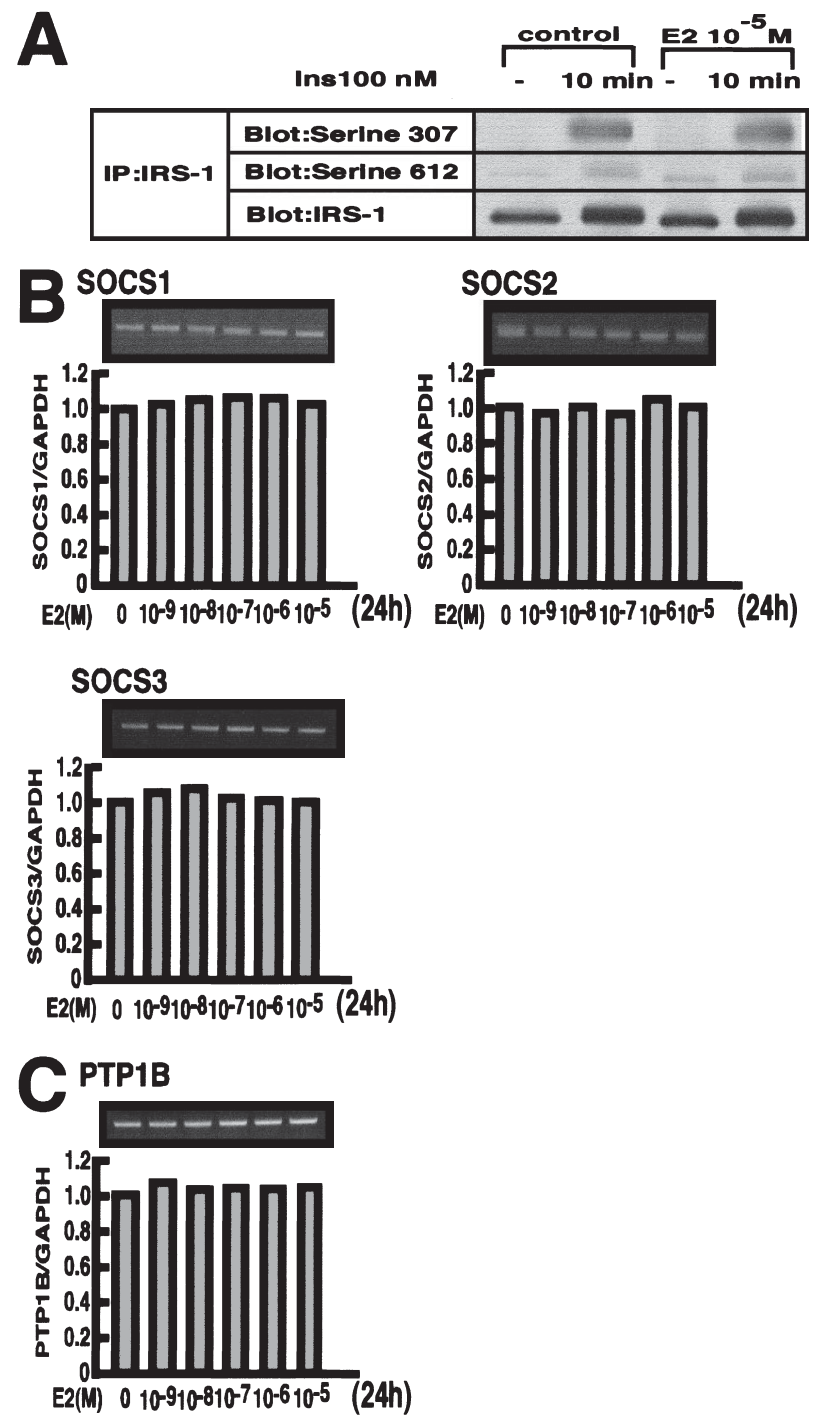

Fig. 5 stimulated glucose transport, and also that cells treated with a relatively low concentration of E2 or PPT $\left(10^{-8}\right.$ M) show increased glucose uptake, without affecting GLUT4 protein expression.

These results are consistent with clinical and experimental observations that estrogen excesses, as in pregnancy $[2,3]$, trans-sexuality [4], and during menstrual cycles [5], or estrogen deficiencies as in aromatase deficient [6] and OVX animals [7], cause insulin resistance. Moreover, a selective ER- $\alpha$ antagonist, MPP, diminished the beneficial effect of E2 at $10^{-8} \mathrm{M}$ on glucose uptake. This observation suggests that ER- $\alpha$ plays a crucial role in maintaining insulin-stimulated glucose uptake during treatment with a relatively low concentration of E2 in mature adipocytes. Unfortunately, the effect of MPP on cells treated with a high concentration of E2 could not be examined, because such an experiment would require a very high concentration of MPP, a competitive antagonist of ER- $\alpha$ [14]. In our 3T3-L1 adipocytes, treatment with PPT produced biphasic effects on insulin stimulated glucose uptake as was observed with E2 treatment. This result again suggests ER- $\alpha$ to be involved in the modulation

Fig. 5. Effects of E2 on IRS-1 serine phosphorylation and SOCS-1, 2, 3 and PTP1B mRNA expressions in mature 3T3-L1 adipocytes.

A: Effects of E2 on IRS-1 protein serine phosphorylation. 3T3-L1 adipocytes were treated with EtOH or E2 $\left(10^{-5} \mathrm{M}\right)$ for $24 \mathrm{~h}$ and then incubated for an additional 10 minutes with or without $100 \mathrm{nM}$ insulin (Ins) at $37^{\circ} \mathrm{C}$. The cells were solubilized, immunoprecipitated and immunoblotted as described in Materials and Methods. To analyze IRS-1 serine phosphorylation, total cell lysates were subjected to immunoprecipitation (IP) with antibody to IRS-1. Resulting precipitates were subjected to immunoblot analysis (IB) with antibody to IRS-1 and the same membrane was then stripped and reblotted with antibodies to anti-IRS-1(phosphoserine 307) and anti-IRS-1(phosphoserine 612). Data are representative of three independent experiments. $\mathrm{B}$ and $\mathrm{C}$ : Effects of E2 on SOCS-1, 2, 3 (B) and PTP1B (C) mRNA expressions. The amounts of these mRNAs were determined by semi-quantitative RT-PCR after incubation of cells for $24 \mathrm{~h}$ with E2 at the concentrations indicated in the figure. PCR products were visualized by ethidium bromide staining after agarose gel electrophoresis and were quantified using NIH image. The amount of each target mRNA was normalized by the amount of GAPDH mRNA, and expressed relative to that of the E2 (-) control. Data are representative of three independent experiments. 
of insulin-stimulated glucose uptake by E2.

The molecular mechanisms by which estrogen modulates glucose uptake in mature adipocytes have not been well established. Collison et al. previously showed, using fully differentiated 3T3-L1 adipocytes, that the decreased glucose uptake associated with estrogens (estrone, estradiol or estriol) was due at least in part to decreased cellular contents and an altered subcellular distribution of IRS proteins, in turn resulting in a reduction in proximal insulin signaling cascades [15]. However, under our experimental conditions, decreased tyrosine phosphorylation of IRS-1 protein occurred without IRS-1 protein degradation even during treatment with high doses of E2 or PPT. Moreover, according to our data, the increased or decreased insulinstimulated glucose transport in response to E2 or PPT is associated with biphasic changes in tyrosine phosphorylation levels of IRS-1, that is consistent with the very recent report [31], and these phenomena appear to be mediated mainly through the ER- $\alpha$ isoform.

Herein, we considered the question of how this modulation of insulin signaling was brought about at the level of IRS-1. The involvement of serine phosphorylation of IRS-1 in the desensitization of insulin action has been pointed out [20-22]. Serine phosphorylation of IRS- 1 could induce conformational changes, steric hindrance and cellular re-localization, leading to the decrease in tyrosine phosphorylation by IR. We first examined the possibility that the reduction of IRS-1 tyrosine phosphorylation by estrogen was due to serine phosphorylation of IRS-1. However, IRS-1 serine phosphorylation did not increase. Given that serine phosphorylation (307 or 612) was not increased, it is unlikely that activation of serine kinases for IRS-1 proteins, such as JNK, Erk, mTOR and S6K [20], were involved, at least on our experimental conditions. However, a very recent report suggested that high concentrations of E2 decrease IRS-1 tyrosine phosphorylation by modulating serine phosphorylation of IRS-1 at serine 307 [31]. The difference in IRS-1 serine phos- phorylation results may be explained by the difference in cell clone, or experimental conditions. In addition, we used 3T3-L1 adipocytes 8 to 11 days after differentiation, while they used cells 14 to 16 days after differentiation. As to the decreased IRS-1 tyrosine phosphorylation, other mechanisms such as association of SOCSs with IRS-1 could be involved [23, 24]. Because ERs are transcriptional factors, we speculated that they might modulate the mRNA levels of these target molecules, and regulate IRS-1 tyrosine phosphorylation. In fact, estrogen reportedly up-regulates SOCS-2 and -3 in hepatocytes via ER- $\alpha$ through mechanisms not involving the estrogen response element [25]. However, in adipocytes, E2 treatment did not up-regulate SOCS-1, -2 or -3 mRNA. This discrepancy is probably attributable to estrogen action depending on intracellular machinery that differs among various cell types $[26,27]$. PTP1B is an important protein phosphatase that is known to regulate IRS-1 tyrosine phosphorylation [28-30]. We also examined PTP1B expression, but it did not change after E2 treatments.

In summary, our data suggest that estrogen, through ER- $\alpha$, modulates insulin-stimulated glucose uptake by regulating tyrosine phosphorylation of IRS-1 protein in mature adipocytes. Further studies are needed to elucidate the mechanisms by which estrogen regulates IRS-1 tyrosine phosphorylation via ER- $\alpha$, as well as to understand the mechanism of glucose intolerance associated with estrogen excess and deficiencies.

\section{Acknowledgements}

This study was supported in part by Grants-in-Aid for Scientific Research (15590939 to S Okuya) from the Ministry of Education, Culture, Sports, Science and Technology of Japan and a grant from Takeda Science Foundation.

\section{References}

1. Livingstone C, Collison M (2002) Sex steroids and insulin resistance. Clin Sci 102: 151-166.

2. Hollingsworth DR (1983) Alterations of maternal metabolism in normal and diabetic pregnancies: differences in insulin-dependent, non insulin-dependent and gestational diabetes. Am J Obst Gynecol 146: 417-429.
3. Tomazic M, Janez A, Sketelj A, Kocijancic A, Eckel J, Sharma PM (2002) Comparison of alterations in insulin signaling pathway in adipocytes from Type II diabetic pregnant women and women with gestational diabetes mellitus. Diabetologia 45: 502-508.

4. Polderman KH, Gooren LJG, Asscheman H, Bakker A, 
Heine RJ (1994) Induction of Insulin Resistance by Androgens and Estrogens. J Clin Endocrinol Metab 79: 265-271.

5. Diamond MP, Simonson DC, DeFronzo RA (1989) Menstrual cyclicity has a profound effect on glucose homeostasis. Fertil Steril 52: 204-208.

6. Takeda K, Toda K, Saibara T, Nakagawa M, Saika K, Onishi T, Sugiura T, Shizuta Y (2003) Progressive development of insulin resistance phenotype in male mice with complete aromatase (CYP19) deficiency. $J$ Endocrinol 176: 237-246.

7. Siri PW, Ginsberg HN (2003) Ovariectomy leads to increased insulin resistance in human apolipoprotein B transgenic mice lacking brown adipose tissue. Metabolism 52: 659-661.

8. Heine PA, Taylor JA, Iwamoto GA, Lubahn DB, Cooke PS (2000) Increased adipose tissue in male and female estrogen receptor- $\alpha$ knockout mice. Proc Natl Acad Sci USA 97: 12729-12734.

9. Cooke PS, Heine PA, Taylor JA, Lubahn DB (2001) The role of estrogen and estrogen receptor- $\alpha$ in male adipose tissue. Mol Cell Endocrinol 178: 147-154.

10. Naaz A, Zakroczymski M, Heine PA, Taylor J, Saunders P, Lubahn D, Cooke PS (2002) Effect of ovariectomy on adipose tissue of mice in the absence of estrogen receptor alpha $(\mathrm{ER} \alpha)$ : a potential role for estrogen receptor beta (ER $\beta)$. Horm Metabol Res 34: 758-763.

11. Dieudonné MN, Leneveu MC, Giudicelli Y, Pecquery R (2004) Evidence for functional estrogen receptors $\alpha$ and $\beta$ in human adipose cells: regional specificities and regulation by estrogens. Am J Physiol-Cell Physiol 286: 655-661.

12. Stauffer SR, Coletta CJ, Tedesco R, Nishiguchi G, Carlson K, Sun J, Katzenellenbogen BS, Katzenellenbogen JA (2000) Pyrazole ligands: structure-affinity/activity relationships of estrogen receptor- $\alpha$-selective agonists. $J$ Med Chem 43: 49344947.

13. Kraichely DM, Sun J, Katzenellenbogen JA, Katzenellenbogen BS (2000) Conformational changes and coactivator recruitment by novel ligands for estrogen receptor- $\alpha$ and estrogen receptor- $\beta$ : correlations with biological character and distinct differences among SRC coactivator family members. Endocrinology 141: 3534-3545.

14. Sun J, Huang YR, Harrington WR, Sheng S, Katzenelllenbogen JA, Katzenellenbogen BS (2002) Antagonists selective for estrogen receptor $\alpha$. Endocrinology 143: 941-947.

15. Collison M, Campbell IW, Salt IP, Dominiczak AF, Connell JMC, Lyall H, Gould GW (2000) Sex hormones induce insulin resistance in 3T3-L1 adipocytes by reducing cellular content of IRS proteins. Diabetologia 43: 1374-1380.
16. Takao T, Nanamiya W, Nazarloo HP, Matsumoto R, Asaba K, Hashimoto K (2003) Exposure to the environmental estrogen bisphenol A differentially modulated estrogen receptor- $\alpha$ and $-\beta$ immunoreactivity and mRNA in male mouse testis. Life Sci 72: 1159-1169.

17. Frost SC, Lane MD (1985) Evidence for the involvement of vicinal sulfhydryl groups in insulin-activated hexose transport by 3T3-L1 adipoyctes. J Biol Chem 260: 2646-2652.

18. Berthois Y, Katzenellenbogen JA, Katzenellenbogen BS (1986) Phenol red in tissue culture media is a weak estrogen: implications concerning the study of estrogenresponsive cells in culture. Proc Natl Acad Sci USA 83: 2496-2500.

19. Wu Z, Xie Y, Morrison RF, Bucher NLR, Farmer SR (1998) PPAR $\gamma$ induces the insulin-dependent glucose transporter GLUT4 in the absence of $\mathrm{C} / \mathrm{EBP} \alpha$ during the conversion of $3 \mathrm{~T} 3$ fibroblasts into adipocytes. $J$ Clin Invest 101: 22-32.

20. Gaul P, Marchand-Brustel YL, Tanti JF (2005) Positive and negative regulation of insulin signaling through IRS-1 phosphorylation. Biochimie 87: 99-109.

21. Aguirre V, Werner ED, Giraud J, Lee YH, Shoelson SE, White MF (2002) Phosphorylation of $\mathrm{Ser}^{307}$ in insulin receptor substrate-1 blocks interactions with the insulin receptor and inhibits insulin action. $J$ Biol Chem 277: 1531-1537.

22. Gaul P, Grémeaux T, Gonzalez T, Marchand-Brustel YL, Tanti JF (2003) MAP kinases and mTOR mediate insulin-induced phosphorylation of Insulin Receptor Substrate- 1 on serine residues 307, 612 and 632. Diabetologia 46: 1532-1542.

23. Ueki K, Kondo T, Kahn CR (2004) Suppressor of cytokine signaling 1 (SOCS-1) and SOCS-3 cause insulin resistance through inhibition of tyrosine phosphorylation of insulin receptor substrate proteins by discrete mechanisms. Mol Cell Biol 24: 5434-5446.

24. Mooney RA, Senn J, Cameron S, Inamdar N, Boivin LM, Shang Y, Furlanetto RW (2001) Suppressors of cytokine signaling-1 and -6 associate with and inhibit the insulin receptor. A potential mechanism for cytokinemediated insulin resistance. J Biol Chem 276: 25889 25893.

25. Leong GM, Moverare S, Brce J, Doyle N, Sjögren K, Dahlman-Wright K, Gustafsson JK, Ho KKY, Ohlsson C, Leung KC (2004) Estrogen up-regulates hepatic expression of suppressors of cytokine signaling-2 and -3 in vivo and in vitro. Endocrinology 145: 5525-5531.

26. Gruber CJ, Tschugguel W, Schneeberger C, Huber JC (2002) Production and actions of estrogens. $N$ Engl J Med 346: 340-352.

27. Smith CL, O'Malley BW (2004) Coregulator function: a key to understanding tissue specificity of selective receptor mudulators. Endocr Rev 25: 45-71.

28. Chen H, Wertheimer SJ, Lin CH, Katz SL, Amrein KE, 
Burn P, Quon MJ (1997) Protein-tyrosine phosphatases PTP1B and Syp are modulators of insulin-stimulated translocation of GLUT4 in transfected rat adipose cells. J Biol Chem 272: 8026-8031.

29. Shimizu S, Maegawa H, Egawa K, Shi K, Bryer-Ash M, Kashiwagi A (2002) Mechanism for differential effect of protein-tyrosine phosphatase 1B on Akt versus mitogen-activated protein kinase in 3T3-L1 adipoctyes. Endocrinology 143: 4563-4569.

30. Gum RJ, Gaede LL, Koterski SL, Heindel M, Clampit
JE, Zinker BA, Trevillyan JM, Ulrich RG, Jirousek MR, Rondinone CM (2003) Reduction of protein tyrosine phosphatase 1B increases insulin-dependent signaling in ob/ob mice. Diabetes 52: 21-28.

31. Nagira K, Saito S, Wada T, Fukui K, Ikubo M, Hori S, Tsuneki H, Kobayashi M, Sasaoka T (2006) Altered subcellular distribution of estrogen receptor $\alpha$ is implicated in estradiol-induced dual regulation of insulin signaling in 3T3-L1 adipocytes. Endocrinology 147: 1020-1028. 